\title{
The Future Prospects for Open Source Business Models In the World of Electric Vehicles
}

\author{
Businesses in which Industry Players Cooperate to Share State-of-the-art Technology
}

\author{
Mamoru Shiiki ${ }^{1}$, Hiroshi Shimizu ${ }^{2}$ \\ ${ }^{1}$ Graduate School of Media and Governance, Keio University \\ 5322 Endo Fujisawa City, Kanagawa/ Japan \\ E-mail:shiiki@sim-drive.com
}

\begin{abstract}
In recent years, a series of incidents have drawn society's attention to issues of environmental awareness and energy security. As a result, electric vehicles (hereafter, "EV") are attracting attention around the world. To stimulate their economies, countries are preparing measures and policies to acquire EV-related core technologies and develop new markets quickly. In this paper, we argue that, given these circumstances, the development of open source businesses in the EV industry will contribute to solving a wide variety of problems, from industry-specific to social issues. Furthermore, we advance the hypothesis that this strategy may prove to be a model both sustainable and profitable. We qualitatively evaluate the utility of our hypothesis on the basis of the SIM-Drive Corporation's actual performance, which has been promoting a similar business model in the EV industry.
\end{abstract}

Keywords: "SIM-Drive" "open source" "in-wheel motor" "Hiroshi Shimizu”

\section{History, Social Issues, and the Auto Industry}

\section{1-1. Social background of the EV boom}

Today, the auto industry is experiencing its third EV boom. The first boom resulted from emission controls established because of serious air pollution in the 1970s. The second boom came about because of the California ZEV (Zero Emission Vehicle) Regulations stemming from air pollution in California. The third boom is an effect of the global financial crisis, increased desire to eliminate dependence on oil, the Kyoto Protocol's carbon dioxide $\left(\mathrm{CO}_{2}\right)$ reduction targets, and smart-grid proposals. We are presently right in the middle of a blooming of full-fledged environmental awareness. The background behind the current boom also includes a technical element, as technologies have been developed to a practical level. Such circumstances have lead to expectations that our society will enhance EV technologies and expand business opportunities. To respond to such expectations, the auto industry, new players from other industries, as well as nations and their governments have begun considering full-scale strategies across a wide range of fields.

\section{1-2. Discrepancy between Social and Industry Needs for EVs}

At this time, $\mathrm{EVs}$ are considered an alternative to conventional gasoline vehicles rather than a new category for which uses must be found by groping in the dark. To ensure widespread EV adoption, we must respond to experienced customers' needs for products, and $\mathrm{EV}$ bodies must realize the same performance with regard to specifications as conventional auto bodies. As for personal mobility, EVs must achieve higher quality, safety, and economic efficiency than conventional gasoline vehicles. 
Shifting to EVs forces upstream industries, including auto and parts manufacturers, to change or discard some of their conventional core technologies in addition to developing new technologies. Such circumstances may result in a big business opportunity; however, such circumstances also carry a high possibility of serious risks. Furthermore, depending on the realized technology level, the industry itself may shrink. Therefore, we are concerned that businesses will not be able to establish stable business models. Because countries and governments must get involved to develop the required infrastructure and laws, one can reasonably assume that enacting such laws will take time. If this causes delays in the construction of infrastructure, this could also become an obstacle standing in the way of nimble business creation.

As just described, there are both high social expectations and high hurdles regarding the realization of EVs.

\section{1-3. Problems in Realizing EVs}

Based on the historical social background and industry trends, we have clarified the problems that must be resolved to satisfy customers' needs. We identified three major barriers.

(1) Technical barrier

Technologies which respond to needs must be standardized and promoted

(2) Business barrier

Developing a new market and defining a business model to ensure continued profits

(3) Environmental barrier

Preparation of infrastructure and laws to accelerate market development

To eliminate the technical barrier, open source technologies, technology platforms, and mass production technologies are important. To eliminate the business barrier, sharing information beyond industry borders, inclusion of user incentives, and the development of sales systems are critical. To eliminate the environmental barrier, resources such as rare earths must be secured and infrastructure and laws must be prepared .

Among these barriers, the technical barrier is particularly important because, depending on the degree of realization, it may influence the size of the market and the pace of infrastructure deployment. Consequently, the industry may not be able to be established unless this barrier is removed. In addition, players inside and outside the industry will place great importance on the business barrier once the technical barrier is eliminated, and thus solving business-barrierrelated problems will also be crucial. We forecast that countries will respond to infrastructure-related problems out of necessity as the technical and business barriers are eliminated. It is therefore essential that the technical and business barriers be eliminated to facilitate the construction of infrastructure.

To make the elimination of both barriers a high priority issue, an alliance must be established for sharing information on state-of-the-art technologies and business plans as well as to quickly develop technical and business infrastructure.

The enhancement and optimization of EVs require many new technical elements which were not present in the conventional auto industry. Expanding to the full-scale use of EVs requires methods for promoting the quick adoption of new technologies and for aggregating and systematizing such technologies. Because vast funds will be required, individual companies may not be able to cover the whole cost of development, delaying the promotion of standardized technologies.

Considering the history of the conventional auto industry, however, we consider the demand for lateral management to be very difficult. Because the industry has thus far tended to pursue differentiation and increased added value through advanced organizational control, the management style has been referred to as a longitudinal business. We strongly believe that the first step which the $\mathrm{EV}$ industry must take is to open up technologies and share information.

\section{1-4 . Development of Open Source Businesses}

As mentioned above, we consider that to accomplish the most important task, the opening up of technologies and the sharing of information, an open source business approach-- a business method often used in the software industry-- is a practicable and effective method.

Thus far, many of the fruits of conventional joint R\&D have been promoted under closed collaborative alliances. With the open source method, however, it is possible to secure achievements and intellectual properties by preparing an appropriate framework while simultaneously expanding the range of participants in collaborative development. In other words, we 
forecast that the open source approach will standardize EV infrastructure technologies and simultaneously allow for the efficient expansion of new businesses.

\section{Application of Open Source Business Models to the Industry} 2-1. General Definitions and Examples An open source business model is a model used to disclose core information, such as knowhow and manufacturing techniques, to collaborating external companies in order to advance collaborative development.

In the IT industry, program code and specifications, which comprise the main knowhow materials, are disclosed so that many companies and freelance developers may participate in low cost development. This stimulates satellite industries and allows for products to be developed more quickly than when product development is controlled by a single company.

Various types of businesses have also been created using the disclosure of core information as their business method.

\section{2-2 . Applicability of Open Source Businesses to EVs}

As stated previously, there are various types of open source businesses. Classifying such businesses allows us to identify the following three points as a recipe for success.

(1) Public benefit (official objective of the scheme)

$\Rightarrow$ contributions to society and industry

(2) Business profitability (back-flow of funds) $\Rightarrow$ securing of sustainable counter values, methods for collecting funds

(3) Securing of the scheme management method

$\Rightarrow$ Clarification of objectives, systematic management of intellectual properties, leadership

Concerning the joint development approaches by open source businesses in the auto industry, the main roadblocks are considered to be loss of value in core technologies and decreased growth due to the transition to the widespread adoption phase. The loss of value from core technologies will influence the initiative of the leadership of major participants during development. In the transition to the widespread adoption phase, it will be difficult to maintain joint development schemes because the attractiveness of intellectual properties and the incentive for achieving development targets will be decreased. In the IT industry, when the growth of open source businesses reaches the widespread adoption phase, it gradually becomes more difficult for individual private companies to maintain open source technologies, at which point such technologies are often transferred from corporate models to nonprofit organizations.

To avoid the loss of such success factors and maintain operations and profits, it is essential to retain the competitive power of core technologies without fail.

\section{Case Studies and Evaluations of Open Source Businesses in the EV Industry}

\section{3-1. The Open Source Business of SIM- Drive Corporation}

Today, there are many Japanese business entities and joint development schemes which are attempting to enter EV development. In addition to the existing auto manufacturers, university research institutes and groups led by companies owning core technologies are approaching EV development in a variety of ways. Among these groups, one example can be found in the SIMDrive Corporation and its SIM-Drive-lead joint $R \& D$ project, in which a business entity is leading EV development as a business.

SIM-Drive Corporation runs a business which aims to achieve the "standardization of technologies" in order to promote the widespread adoption of EVs by using a key EV component as a core, the in-wheel motor (an EV-dedicated wheel featuring an integrated drive mechanism operated by an electric motor), which is a technology developed by Mr. Hiroshi Shimizu, President of SIM-Drive Corporation and Professor of Keio University.

SIM-Drive Corporation's business continues to promote such an open source process by asking various external companies, such as auto manufacturers and parts manufacturers, to join their project and share information on state-of-theart technologies as they develop and demonstrate an EV prototype. To join a project, a company must pay 20,000,000 yen (approximately $\$ 250,000$ USD) per project. Generally, companies must spend billions of yen to achieve such developments. But because in this case a number of companies participate in the project, it is 
possible to reduce each company's financial burden. Participating companies can acquire state-of-the-art technologies and knowhow by making a small investment, which is a very useful opportunity for them. Participating companies can mass-produce a prototype vehicle if the company pays an additional fee. Thus, this business model creates a system where fees are paid according to the whole vehicle and the volume of sales (see Fig. 1).

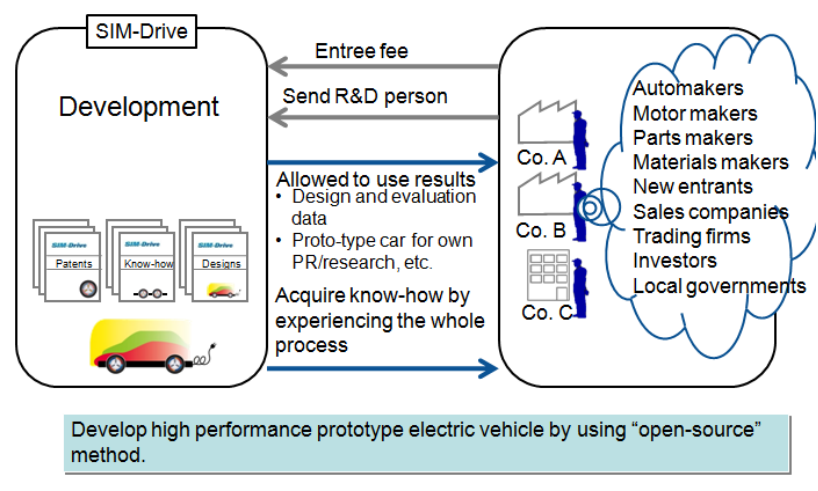

Fig.1:SIM-Drive Corporation's Business

\section{3-2. Overview of an Evaluation of One of SIM-Drive Corporation's Joint Development Schemes}

To evaluate the company's joint development scheme, we focused our attention on the three key points of open source businesses and objectively evaluated such points. The results appear to correspond to the three points. The details of the evaluation are as follows.

(1) Public Benefits of Widespread EV Adoption The joint development scheme managed by SIMDrive Corporation provides an open laboratory as well as aggregation and disclosure of technologies, which is difficult for a single company to achieve, in order to contribute and hasten the widespread adoption of EVs, which is a social need.

\section{(2) Business Profitability}

SIM-Drive Corporation, the company hosting this scheme, has succeeded in effectively using their intellectual property (advanced in-wheel motor technology) by collecting participation fees from participating companies in exchange for their technology.

In particular, SIM-Drive Corporation has been strategically moving ahead with development of a layout platform for EV components that may be realized for the first time with the company's technologies. This not only continuously strengthens the added value of their technologies, but also consolidates the technologies of participating companies, leading to a standardization strategy which could not be achieved by one company acting alone. Participating companies can promote combinations of their intellectual properties together in such a scheme, providing a mechanism to synergistically enhance added value and to control the result and direction of standardization.

From a long-term standpoint, however, it may be difficult to permanently secure fees when the inwheel motor technology reaches a certain level of market penetration.

(3) Evaluation of Scheme Management Methods SIM-Drive Corporation's scheme management, in which they exercise strong leadership over their core technology, can be said to be open with respect to results and collateral. The continuing advance of the company's in-wheel motor technology, the key to their scheme management, is a model in which necessary funds are secured by scheme participation fees paid by participating companies and necessary technologies are realized through prototypes produced through the scheme. They have established a profitable model by additionally filing patent applications for products and knowhow obtained through the project.

\section{3-3 . SIM-Drive Corporation's Actual Performance}

Concerning the above-mentioned hypothesis, SIM-Drive Corporation successfully realized its first project during the period from January 18, 2010 to March 31, 2011 and has reported on its actual performance. 34 organizations joined together to produce a prototype vehicle, SIM-LEI (see Fig. 2).

They list the following results for actual performance. The prototype vehicle matched the same level of specifications as for gasoline (GS) vehicles. Also, a new technology to minimize the loss of energy was developed to increase driving performance. It is also possible to handle energy security in environment. The technologies encourage participating companies to catch up to the state-of-the-art through applied work, rendering it possible to transfer knowhow to the participants with confidence. In terms of the industry shift toward lateral business models, which has been regarded as an important challenge, 
SIM-Drive Corporation has reported that it has successfully established a new network among companies. As for the sustainability of their business, they are now promoting their second project, and thus continuity has been assured.

The above reasons demonstrate that the actual performance of SIM-Drive Corporation's first project corresponds to issues concerning the quick growth of the EV industry and industryspecific problems, as well as providing solutions to them. These reasons also demonstrate that the actual performance is sufficient to realize a profitable business and that there are good signs regarding the staying power of the business.

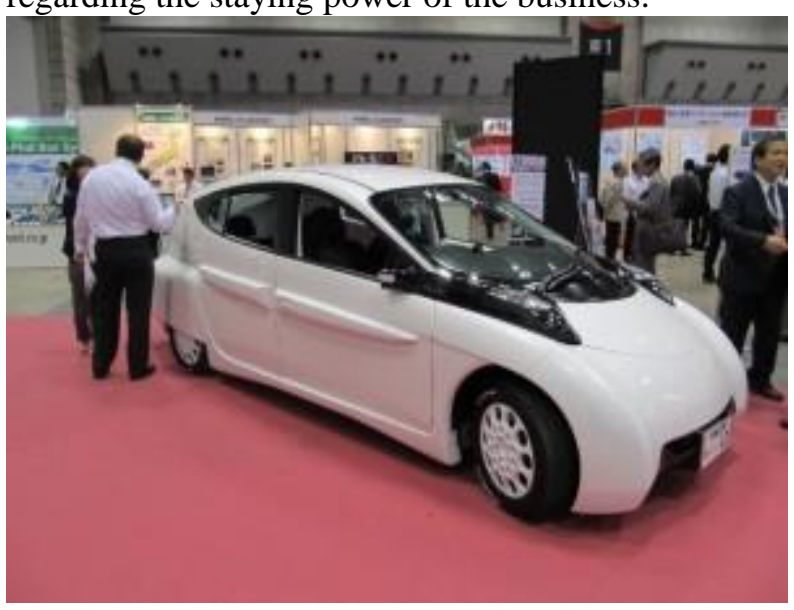

Fig.2:Prototype Vehicle SIM-LEI

\section{Conclusion}

As has been the case for the SIM-Drive Corporation described in this paper as an example of an open source business, a joint development scheme centering on core technologies can not only maintain its technologies' added values but also promote the development of associated industries as well as contribute indirectly to the environment, which has been a growing issue in recent years. Additionally, the business model includes the success factors of conventional open source businesses, suggesting its profitability. The excellence of this business model is that it plays the role of a hub in the shift from longitudinal to lateral business models, which is currently required in the industry. SIM-LEI, the result of the first project, is a concrete example of our hypothesis.

In the EV industry, where quick and efficient responses to social needs are required, the open source business can be considered highly effective with respect to both public benefit and the business aspects. Like the business model which SIM-Drive Corporation especially is promoting, tailoring and optimizing management methods to the state of the industry allows one to acquire a greater advantage with one's business model.

\section{Author}

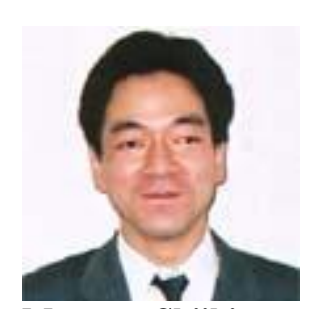

\section{Mamoru Shiiki}

Doctor's course

Graduate School of Media and Governance, Keio University

Tel:+81-44-201-1014

Fax:+81-44-599-6444

Email:shiiki@sim-drive.com

URL:http://www.sim-drive.com/

Director of Administration Office

Association for the Promotion of Electric Vehicles

Specialization: , Electric Vehicle, Marketing, strategy

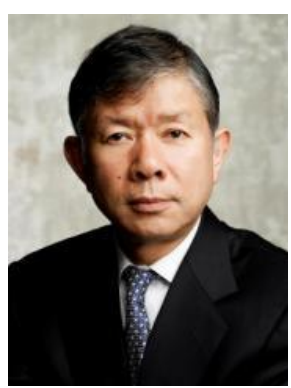

Hiroshi Shimizu

Professor Faculty of Environment and Information Studies Graduate School of Media and Governance Keio University

Tel:+81-44-580-1565

Fax: +81-44-580-1435

Email: hiros@sfc.keio.ac.jp

URL: http://www.eliica.com/

Specialization: Environmental Technology, Electric Vehicle 